\title{
Urinary tract infection in small children: the evolution of renal damage over time
}

\author{
Svante Swerkersson $^{1}$ (D) $\cdot$ Ulf Jodal $^{1} \cdot$ Rune Sixt $^{2} \cdot$ Eira Stokland $^{3} \cdot$ Sverker Hansson $^{1}$
}

Received: 20 March 2017 /Revised: 1 May 2017 / Accepted: 11 May 2017 / Published online: 5 July 2017

(C) The Author(s) 2017. This article is an open access publication

\begin{abstract}
Background Our objective was to analyze the evolution of kidney damage over time in small children with urinary tract infection (UTI) and factors associated with progression of renal damage.

Methods From a cohort of 1003 children $<2$ years of age with first-time UTI, a retrospective analysis of 103 children was done. Children were selected because of renal damage at index ${ }^{99 \mathrm{~m}} \mathrm{Tc}$-dimercaptosuccinic acid (DMSA) scintigraphy at least 3 months after UTI, and a late DMSA scan was performed after at least 2 years. Damage was classified as progression when there was a decline in differential renal function (DRF) by $\geq 4 \%$, as regression when there was complete or partial resolution of uptake defects.

Results Of 103 children, 20 showed progression, 20 regression, and 63 remained unchanged. There were no differences between groups regarding gender or age. In the progression group, 16/20 (80\%) children had vesicoureteral reflux (VUR) grade III-V and $13(65 \%)$ had recurrent UTI. In multivariable regression analysis, both VUR grade III-V and recurrent UTI were associated with progression. In the regression group, 16/20 (80\%) had no VUR or grade I-II, and two (10\%) had recurrent UTI.
\end{abstract}

Svante Swerkersson

svante.swerkersson@gu.se

1 Department of Pediatric Uronephrologic Center, Sahlgrenska Academy, The Queen Silvia Children's Hospital, Sahlgrenska University Hospital, 41685 Göteborg, Sweden

2 Department of Pediatric Clinical Physiology, Sahlgrenska Academy, The Queen Silvia Children's Hospital, Sahlgrenska University Hospital, Göteborg, Sweden

3 Department of Pediatric Radiology, Sahlgrenska Academy, The Queen Silvia Children's Hospital, Sahlgrenska University Hospital, Göteborg, Sweden
Conclusions Most small children with febrile UTI do not develop renal damage and if they do the majority remain unchanged or regress over time. However, up to one-fifth of children with renal damage diagnosed after UTI are at risk of renal deterioration. These children are characterized by the presence of VUR grades III-V and recurrent febrile UTI and may benefit from follow-up.

Keywords Urinary tract infection · Children · Vesicoureteral reflux $\cdot$ Renal damage

\section{Introduction}

Urinary tract infection (UTI) in children can be associated with renal damage. The frequency of renal damage found at ${ }^{99 \mathrm{~m}}$ Tc-dimercaptosuccinic acid (DMSA) scintigraphy 5 months to 2 years after UTI is around 20\%, but the proportion varies between different studies [1]. The risk of renal damage may be increased in children with malformations, high-grade vesicoureteral reflux (VUR), and recurrent febrile UTI [2-6]. Moreover, there seems to be a gender variation, where boys more often have congenital renal damage associated with VUR, whereas in girls acquired focal damage related to recurrent UTI is more common [7, 8]. Infections may cause transient inflammatory changes in the kidney that resolve within 3-6 months [9-11].

Studies of long-term consequences of renal damage have shown varying results. While some earlier studies found increased frequency of hypertension, impaired renal function, and pregnancy-related complications, a comprehensive meta-analysis of conducted studies could not confirm these results [12]. However, a study of 86 women with 35 years of follow-up found significant decrease in kidney function and increased frequency of hypertension in those with bilateral 
and severe renal scarring $[13,14]$. Despite many studies concerning different aspects of kidney damage, few have analyzed the evolution of damage over time and the conclusions have been diverging [15-18].

The aim of this study was to describe the evolution of kidney damage in small children with UTI and to analyze possible factors associated with progression. The focus has been on permanent renal damage that persisted beyond 3 months of the index UTI.

\section{Methods}

This study is a retrospective analysis of small children with kidney damage found on DMSA scintigraphy performed at least 90 days after their first symptomatic UTI, here referred to as index DMSA, and who all had a follow-up DMSA scan more than 2 years after the index UTI. They all belonged to a population-based cohort of 1003 children below 2 years of age diagnosed with a first-time symptomatic UTI at the emergency room of the Queen Silvia Children's Hospital, Göteborg, from 1994 through 2003. Excluded were children with asymptomatic bacteriuria, urinary tract obstruction, urogenital malformation, neurogenic bladder, and severe neurological or systemic disease. The UTI investigation protocol recommended ultrasound, voiding cystourethrography (VCUG), and DMSA scan.

Clinical and laboratory parameters at the index infection, including highest measured temperature, highest $\mathrm{C}$-reactive protein (CRP), bacterial findings, and the number of febrile recurrences, were recorded. The diagnosis of UTI required bacteriuria of a single species of at least 100,000 colony-forming units (CFU)/ml in two midstream or bag samples, 10,000 CFU/ $\mathrm{ml}$ or more in one catheter sample or any bacterial growth in urine obtained by suprapubic aspiration. Febrile recurrence was defined as UTI with temperature of $38.5^{\circ} \mathrm{C}$ or more. The VCUGs were revaluated by the same pediatric radiologist (ES) and the DMSA scans by the same nuclear medicine specialist (RS). VUR was classified according to the International Reflux Study in Children [19]. In case of bilateral VUR, the highest grade was used to classify each case.

DMSA scan was performed according to European guidelines [20]. Kidneys were classified as normal if differential renal function (DRF) was $45 \%$ or more and if there was no up-take defect, as a minor defect if DRF was $45 \%$ or more with one or more up-take defects, as a moderate defect if DRF was $40 \%$ to $45 \%$, and as a pronounced defect if DRF below $40 \%$. If there were bilateral defects or renal duplication, arbitrary classification was done to the same categories. The evolution of the kidney damage was classified into three groups: (1) progression if $\geq 4 \%$ decline of DRF between the index and the last DMSA scan, (2) regression if isotope up-take defects, diagnosed by visual evaluation, on the index DMSA scan were partially or completely resolved at follow-up, (3) unchanged in the remaining cases.

The median time between the index UTI and the index DMSA scan was 8 months (range, 3-61 months) and between the index UTI and the last follow-up DMSA scan 96 months (range, 26-210 months). In 37 children, the index DMSA scan was performed between 3 and 6 months after the index UTI. Of these, seven were classified as regression, 22 as unchanged, and eight as progression at the last follow-up DMSA scan. Corresponding figures when index DMSA scan was performed more than 6 months after UTI showed similar proportions $(13,41$, and 12 , respectively, $p=0.74)$.

\section{Statistics}

Distribution of continuous variables is given as median, minimum, and maximum and categorical variables as number and percentage. For comparison between the three groups of evolution of kidney damage, the Mantel-Haenszel Chi-square test was used for dichotomous and ordered variables and the Spearman correlation test for continuous and ordered variables. In the assessment of factors associated with progression of kidney damage, univariable analysis was done by logistic regression and all significant univariable variables were entered into a multivariable stepwise logistic analysis. All significance tests were two-sided and conducted at the 5\% significance level. The statistical analyses were performed using SAS® software version 9.3.

\section{Results}

The original cohort consisted of 1003 children (Fig. 1). In 778, the DMSA scan was performed 90 days or more after the index UTI. In 575 of these 778 children, the DMSA scan was normal and not repeated. In 203 children (26\%), the DMSA scan showed damage. In comparison with children with a normal DMSA scan, the age and gender distribution were similar, while non-E.coli infection, recurrent UTI, and high-grade VUR were more prevalent in the group with renal damage (Table 1). The kidney damage was classified as minor in $124(61 \%)$ children.

Of the 203 children with renal damage, 92 did not have a follow-up DMSA after 2 years (minor damage in 77\%) (Fig. 1). Because of difficulty in interpreting progression of kidney damage, eight children were excluded (two with of horseshoe kidney, one with nephrectomy, and five with heminephrectomy). Thus, 103 children were included, 46 boys and 57 girls, with persistent renal damage 90 days or more after the index UTI and who also had a follow-up DMSA scan after a minimum of 2 years. The median age at the index UTI was 3 months (range, $0.3-17$ months) for boys and 8 months (range, $0.7-22$ months) 
Fig. 1 Flow chart of included patients. DMSA

dimercaptosuccinic acid, UTI urinary tract infection

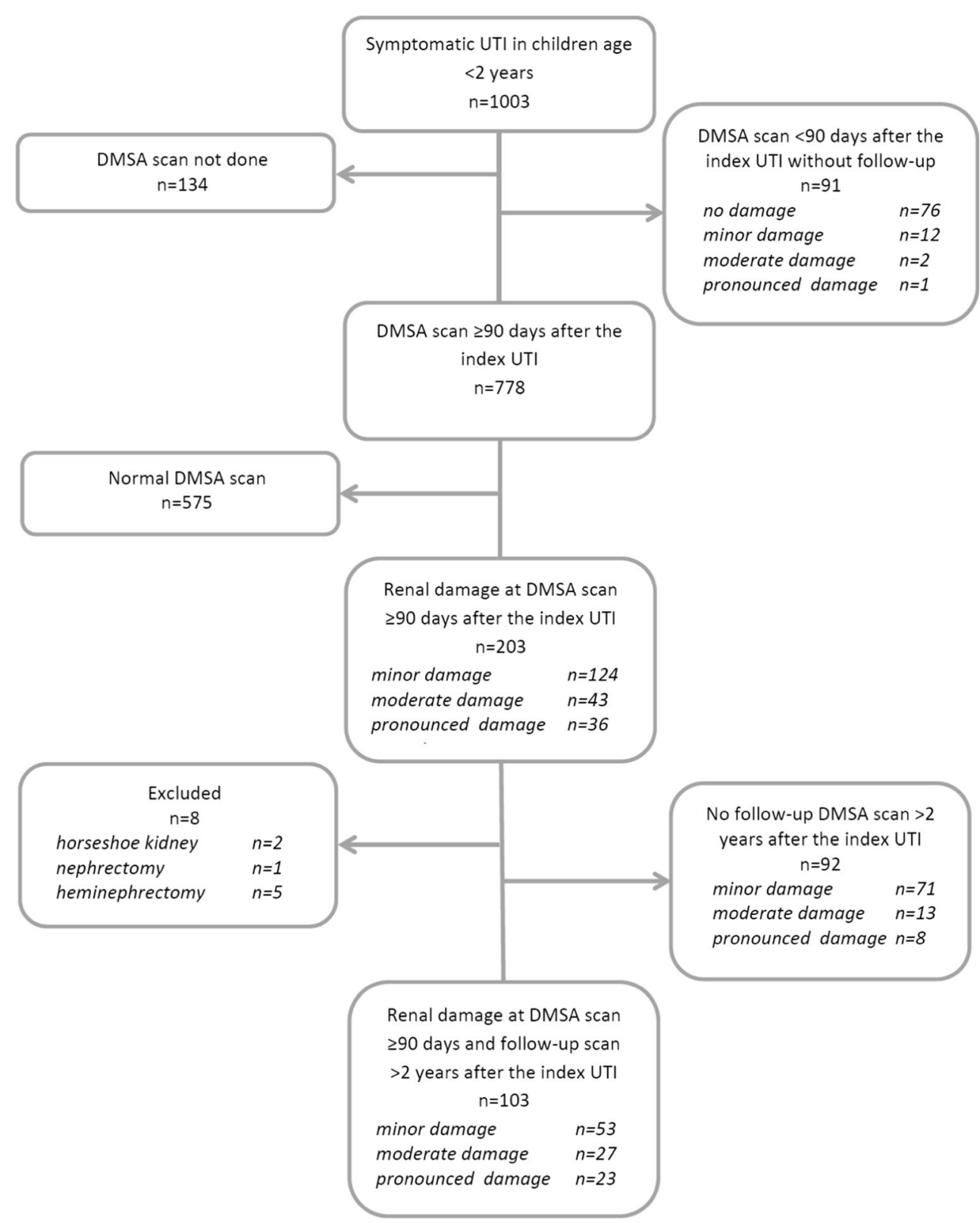

for girls. The renal damage was minor in 53, moderate in 27 and pronounced in 23 at index DMSA scan. There was a significant gender difference. Among boys, minor damage was found in $20(44 \%)$, moderate in ten $(22 \%)$, and pronounced in $16(35 \%)$, while corresponding figures for girls were 33 $(58 \%), 17(30 \%)$, and seven $(12 \%)$, respectively $(p=0.02)$. Of the 100 children investigated with VCUG, 38 had no VUR, 14 had grade I-II, and 48 had grade III-V. Recurrent febrile UTI occurred in 34 children, 13 boys and 21 girls.

The clinical data for the three groups concerning evolution of kidney damage are given in Table 2. There were no differences between the groups regarding gender, age, highest temperature, or highest CRP at the index UTI.

The regression group comprised 20 children, nine boys and 11 girls. Ten children had complete resolution of isotope up- take defects. Of those, eight had minor and two moderate damage at the index DMSA scan. One child had VUR grade II, while the others had no VUR. Among the ten children with partial resolution, three had minor, five moderate, and three pronounced damage, and one child had VUR grade II, one grade III, and two grade IV.

In the majority $(61 \%)$ of children with kidney damage at the index DMSA scan, renal status remained unchanged over time.

\section{Risk of progression}

The progression group comprised 20 children, ten boys and ten girls. This group was compared with the pooled unchanged and regression groups in univariable analyses 
Table 1 Clinical data of children with and without renal damage at DMSA scan performed $\geq 90$ days after the index UTI

\begin{tabular}{|c|c|c|c|}
\hline & Without damage $(n=575)$ & With damage $(n=203)$ & $p$ value \\
\hline \multicolumn{4}{|l|}{ Gender } \\
\hline Boys & 286 & 92 & \multirow[t]{2}{*}{0.29} \\
\hline Girls & 289 & 111 & \\
\hline \multicolumn{4}{|l|}{ Index UTI } \\
\hline \multicolumn{3}{|l|}{ Age, months, } & 0.53 \\
\hline CRP highest, mg/l median (range) & $62(5-350)$ & $120(5-430)$ & $<0.0001$ \\
\hline \multicolumn{4}{|l|}{ Bacterial species } \\
\hline E. coli, $n(\%)$ & $542(94 \%)$ & $178(88 \%)$ & \multirow[t]{3}{*}{0.0046} \\
\hline Other Gram-negative sp. & 28 & 16 & \\
\hline Other sp. & 5 & 9 & \\
\hline Recurrent UTI, $n(\%)$ & $65(11 \%)$ & $43(21 \%)$ & 0.0005 \\
\hline \multicolumn{4}{|l|}{ VUR, $n(\%)$} \\
\hline $\begin{array}{l}\text { No VUR } \\
\text { Grade I }\end{array}$ & $\begin{array}{l}484(88 \%) \\
22(4 \%)\end{array}$ & $\begin{array}{l}111(56 \%) \\
9(5 \%)\end{array}$ & \multirow{6}{*}{$<0.0001$} \\
\hline Grade II & $28(5 \%)$ & $18(9 \%)$ & \\
\hline Grade III & $15(3 \%)$ & $25(13 \%)$ & \\
\hline Grade IV & $4(1 \%)$ & $31(16 \%)$ & \\
\hline Grade V & 0 & $4(2 \%)$ & \\
\hline VCUG not done & 22 & 5 & \\
\hline \multicolumn{4}{|l|}{ Renal damage, $n(\%)$} \\
\hline Minor & & $124(61 \%)$ & \\
\hline Moderate & & $43(21 \%)$ & \\
\hline Pronounced & & $36(18 \%)$ & \\
\hline
\end{tabular}

$D M S A$ dimercaptosuccinic acid, UTI urinary tract infection, $C R P$ C-reactive protein, sp. species, VUR vesicoureteral reflux, $V C U G$ voiding cystourethrography
(Table 3). Children with moderate or pronounced renal damage at index DMSA scan had a significantly higher risk of progression, 15 of 50 (30\%), than children with minor damage, 5 of $53(9 \%)(p=0.01)$. Also, children with VUR grade III-V had a higher risk of progression, 16 of 48 (33\%), than children with no VUR or VUR I-II, 4 of $52(8 \%)$ $(p=0.002)$ (Fig. 2).

Progression was significantly related to recurrence of UTI, 13 of $34(38 \%)$ compared to 7 of $69(10 \%)$ without recurrence $(p=0.001)$. Recurrence was also significantly related to grade of VUR; in children without VUR, four of $38(11 \%)$ had recurrence, in VUR I-II 7 of $14(50 \%)$ and in VUR III-V 23 of $48(48 \%)(p<0.001)$. Antibacterial prophylaxis was given to 43 of the children with VUR grade III-V with a median duration of 20 months.

In multivariable logistic regression analysis, both VUR grade III-V and recurrent febrile UTI were significantly associated with progression of kidney damage $(p=0.011$ and $p=0.001$, respectively) (Table 3 ). When boys and girls were analyzed separately, there was a significant association only for VUR grade III-V in boys, odds ratio 10.7 (95\% CI 1.293.6) ( $p=0.013)$, while for girls there was a significant association with both recurrent febrile UTI, odds ratio 9.9 (95\% CI
1.7-58.1) $(p=0.003)$ and moderate to pronounced damage at the index DMSA scan, odds ratio 7.3 (95\% CI 1.2-43.6) $(p=0.019)$.

In the progression group, the mean decrease of DRF in the damaged kidney between the index and the last DMSA scan was $6 \%$ (range, 4-10\%).

\section{Discussion}

Few studies have investigated the progress of renal damage over time by repeated DMSA scans. In the European branch of the International Reflux Study in Children, Piepsz et al. analyzed the results of serial DMSA scans. A decrease of $\geq 4 \%$ of DFR was chosen as deterioration as it represented one standard deviation at ${ }^{99 \mathrm{~m}} \mathrm{Tc}$-mercaptoacetyltriglycine scintigraphy $[15,21]$. Five-year follow-up was performed in 287 children, all with VUR grade III-IV treated with either prophylaxis or surgery. A reduction of $\geq 4 \%$ of DRF occurred in $31(11 \%)$ children, while improved scintigraphic image was seen in eight $(3 \%)$. Deterioration was more frequent in bilateral VUR grade IV compared to unilateral grade IV or grade III VUR, in children with febrile recurrence and in children 
Table 2 Comparison between the three groups of renal damage evolution concerning clinical parameters at the index UTI, number of recurrent UTI, presence of duplex, renal damage at the index DSMA scan, and status of vesicoureteral reflux

\begin{tabular}{|c|c|c|c|c|}
\hline & Progression $(n=20)$ & Regression $(n=20)$ & Unchanged $(n=63)$ & $p$ value \\
\hline Gender, boys $n(\%)$ & $10(50 \%)$ & $9(45 \%)$ & $27(43 \%)$ & 0.75 \\
\hline \multicolumn{5}{|l|}{ Index UTI } \\
\hline Age, months median (range) & $5.5(1.3-16.0)$ & $4.6(0.5-22.0)$ & $6.5(0.3-21.4)$ & 0.70 \\
\hline CRP, highest, mg/median (range) & $135(23-430)$ & $110(5-210)$ & $120(5-300)$ & 0.32 \\
\hline \multicolumn{5}{|l|}{ Bacterial species } \\
\hline E.coli, $n(\%)$ & $12(60 \%)$ & $18(90 \%)$ & $55(87 \%)$ & \multirow[t]{2}{*}{0.013} \\
\hline Non-E.coli sp. & 8 & 2 & 8 & \\
\hline Recurrent febrile UTI, $n(\%)$ & $13(65 \%)$ & $2(10 \%)$ & $19(30 \%)$ & $<0.001$ \\
\hline \multicolumn{5}{|c|}{ Renal damage at index DMSA scan, $n(\%)$} \\
\hline Minor & $5(25 \%)$ & $11(55 \%)$ & $37(59 \%)$ & \multirow{3}{*}{0.048} \\
\hline Moderate & $9(45 \%)$ & $7(35 \%)$ & $11(17 \%)$ & \\
\hline Pronounced & $6(30 \%)$ & $2(10 \%)$ & $15(24 \%)$ & \\
\hline \multicolumn{5}{|l|}{ VUR, $n(\%)$} \\
\hline no VUR & $1(5 \%)$ & $14(70 \%)$ & $23(37 \%)$ & \multirow{4}{*}{$<0.001$} \\
\hline VUR grade I to II & $3(15 \%)$ & $2(10 \%)$ & $9(14 \%)$ & \\
\hline VUR grade III to V & $16(80 \%)$ & $3(15 \%)$ & $29(46 \%)$ & \\
\hline VCUG not done & & 1 & 2 & \\
\hline
\end{tabular}

UTI urinary tract infection, $C R P$ C-reactive protein, $s p$. species, DMSA dimercaptosuccinic acid, VUR vesicoureteral reflux, VCUG voiding cystourethrography

under 2 years of age. In a study by Sjöström et al., 108 children with VUR grade III-V were followed for 5 years by repeated renal scintigraphy [17]. A deteriorated DRF of $>6 \%$ was seen in $18 \%$, while $5 \%$ showed recovery of focal lesions. Predictive factors for deterioration were prenatal diagnosis, reduced glomerular filtration rate from the start, breakthrough infections, and grade IV to V VUR.
Furthermore, in the Swedish Reflux Trial, 203 children with VUR grade III-IV randomized to prophylaxis, endoscopic surgery, or surveillance were followed for 2 years [16]. New up-take defects or $\geq 4 \%$ decrease in DRF was observed in $24(12 \%)$ children, of whom 15 had recurrent UTI. The patients in these studies were all selected because of high-grade VUR.

Table 3 Univariable logistic and multivariable stepwise logistic regression analysis of probable explaining factors for progression of kidney damage. In the analyses, the progression group is compared with the combined groups of regression and unchanged damage

\begin{tabular}{|c|c|c|c|c|}
\hline & \multicolumn{2}{|l|}{ Univariable analysis } & \multicolumn{2}{|l|}{ Multivariable analysis* } \\
\hline & Odds ratio $(95 \% \mathrm{CI})$ & $p$ value & Odds ratio $(95 \% \mathrm{CI})$ & $p$ value \\
\hline \multicolumn{5}{|l|}{ Bacteriology at the index UTI } \\
\hline E. coli (reference) & 1.0 & & & \\
\hline Non-E.coli & $4.9(1.6-14.8)$ & 0.005 & & \\
\hline \multicolumn{5}{|c|}{ Renal damage at index DMSA scan } \\
\hline Minor (reference) & 1.0 & & & \\
\hline Moderate or pronounced & $4.11(1.4-12.4)$ & 0.012 & & \\
\hline \multicolumn{5}{|l|}{ VUR } \\
\hline Grade 0-II (reference) & 1.0 & & & \\
\hline Grade III-V & $6.0(1.8-19.6)$ & 0.003 & $4.5(1.3-15.3)$ & 0.011 \\
\hline \multicolumn{5}{|l|}{ Recurrent UTI } \\
\hline No (reference) & 1.0 & & & \\
\hline Yes & $5.5(1.9-15.6)$ & 0.001 & $3.8(1.3-11.5)$ & 0.001 \\
\hline
\end{tabular}

*Area under the ROC curve was 0.77 with the variables in the multivariable model.

$C I$ confidence interval, UTI urinary tract infection, DMSA dimercaptosuccinic acid, VUR vesicoureteral reflux 


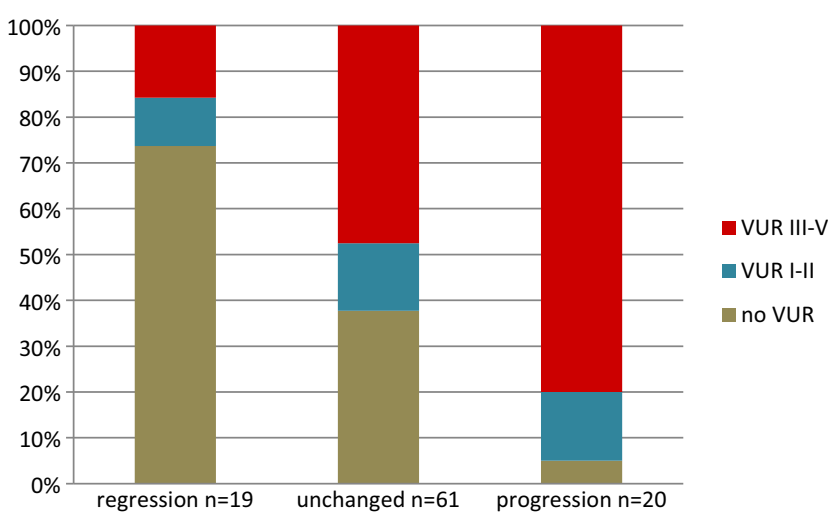

Fig. 2 Grade of vesicoureteral reflux related to evolution of renal damage. $V U R$ vesicoureteral reflux

In a prospective study by Parvex et al., 50 children 0 to 18 years presenting with DMSA scan defect at 6 months after the first episode of acute pyelonephritis were followed for 3 years [18]. The aim was to analyze the progression of renal scarring over time and its impact on renal growth. In total, 88 renal units showed focal scars on DMSA scan at 6 months. Of these, $64(72 \%)$ had improved at 3-year follow-up; 56 (63\%) had partial, and eight (9\%) complete resolution, while 24 (27\%) remained unchanged. No relationship between degree of VUR and resolution was observed. The high resolution rate reported by Parvex et al. could not be confirmed in our study. Instead, regression of renal damage was found in only $19 \%$ of the children. However, many children with minor renal damage were excluded as they did not have a follow-up DMSA scan. The material described by Parvex et al. might have been of a more benign nature, which is also reflected by a lower percentage of VUR, 36 vs. $63 \%$, in the present study.

Even though renal damage remained unchanged over time in the majority of children, progression occurred in $19 \%$. This is similar to the $11-18 \%$ observed in the reflux studies cited above. The risk factors for progression were non- $E$. coli at the index infection, moderate to pronounced renal damage at the index DMSA scan, high-grade VUR and recurrent febrile UTI. However, when performing multivariable regression analysis, only VUR and recurrent UTI remained significant. Furthermore, there was a gender difference where VUR was important for boys and both recurrence and initial damage for girls. Interestingly, there was no relationship between evolution of renal damage and gender, age or degree of inflammation at the index UTI.

This study has some limitations. It is retrospective. The follow-up time is variable, as is the time to investigation. Also there was a substantial number of patients lost to follow-up, but most of these had minor renal damage. Up-take defects found on DMSA scan performed early after acute UTI may be transient. There are different opinions on the optimal time interval between UTI and visualization of permanent renal damage on DMSA scan. While Goldraich et al. recommended an interval of at least 3 months, others have found resolution of defects 6 to 12 months after an acute UTI [9-11, 22]. We used a 90day interval. There was no significant difference in final renal outcome between DMSA scan performed at 3 to 6 months compared to later after the index UTI. Still, the interval chosen may have influenced the rate of regression. It may be that kidneys under normal resolution of acute damage have been regarded as regression. Speculatively, another explanation could be hypertrophy of surrounding renal parenchyma decreasing the appearance of the isotope up-take defect. As in other studies using DMSA scans for detecting renal damage, it is not possible to differentiate between congenital and acquired damage. However, it is likely that congenital renal damage may also progress.

This study describes deterioration of 4 to $10 \%$ in DRF during a follow-up time of 2 to 18 years in $19 \%$ of small children with renal damage diagnosed after UTI. The long-term impact of this is unclear. Studies of children with renal damage followed into adulthood have presented conflicting results, where some have shown few complications [12] while others a substantial risk of hypertension [14].

\section{Conclusions}

Most small children with febrile UTI do not develop renal damage and if they do the majority remain unchanged or regress over time. However, up to one-fifth of children with renal damage diagnosed after UTI are at risk of renal deterioration. These children are characterized by the presence of VUR grade III-V and recurrent febrile UTI and may benefit from follow-up.

Acknowledgments We thank Tina Linnér for coordinating, collecting, and entering the data in the files and Aldina Pilovic for assistance with the statistics.

\section{Compliance with ethical standards}

Funding The study was supported by the Swedish government under the agreement between the government and the county councils concerning support of medical research and education, the Queen Silvia Children's Hospital Research Foundation, and the Freemason Foundation.

Conflict of interest The authors declare no conflicts of interest.

Ethics The study was approved by the Regional Ethical Review Board in Gothenburg (278-08). 
Open Access This article is distributed under the terms of the Creative Commons Attribution 4.0 International License (http:// creativecommons.org/licenses/by/4.0/), which permits unrestricted use, distribution, and reproduction in any medium, provided you give appropriate credit to the original author(s) and the source, provide a link to the Creative Commons license, and indicate if changes were made.

\section{References}

1. Shaikh N, Ewing AL, Bhatnagar S, Hoberman A (2010) Risk of renal scarring in children with a first urinary tract infection: a systematic review. Pediatrics 126:1084-1091

2. Mattoo TK (2011) Vesicoureteral reflux and reflux nephropathy. Adv Chronic Kidney Dis 18:348-354

3. Swerkersson S, Jodal U, Sixt R, Stokland E, Hansson S (2007) Relationship among vesicoureteral reflux, urinary tract infection and renal damage in children. J Urol 178:647-651 discussion 650-641

4. Chen JJ, Pugach J, West D, Naseer S, Steinhardt GF (2003) Infant vesicoureteral reflux: a comparison between patients presenting with a prenatal diagnosis and those presenting with a urinary tract infection. Urology 61:442-446 discussion 446-447

5. Bush NC, Keays M, Adams C, Mizener K, Pritzker K, Smith W, Traylor J, Villanueva C, Snodgrass WT (2015) Renal damage detected by DMSA, despite normal renal ultrasound, in children with febrile UTI. J Pediatr Urol 11(126):e121-e127

6. Silva JM, Santos Diniz JS, Marino VS, Lima EM, Cardoso LS, Vasconcelos MA, Oliveira EA (2006) Clinical course of 735 children and adolescents with primary vesicoureteral reflux. Pediatr Nephrol 21:981-988

7. Yeung CK, Godley ML, Dhillon HK, Gordon I, Duffy PG, Ransley PG (1997) The characteristics of primary vesico-ureteric reflux in male and female infants with pre-natal hydronephrosis. Br J Urol 80:319-327

8. Wennerstrom M, Hansson S, Jodal U, Stokland E (2000) Primary and acquired renal scarring in boys and girls with urinary tract infection. J Pediatr 136:30-34

9. Ditchfield MR, Summerville D, Grimwood K, Cook DJ, Powell HR, Sloane R, Nolan TM, de Campo JF (2002) Time course of transient cortical scintigraphic defects associated with acute pyelonephritis. Pediatr Radiol 32:849-852
10. Goldraich NP, Goldraich IH (1995) Update on dimercaptosuccinic acid renal scanning in children with urinary tract infection. Pediatr Nephrol 9:221-226 discussion 227

11. Jakobsson B, Svensson L (1997) Transient pyelonephritic changes on ${ }^{99 \mathrm{~m}}$ Technetium-dimercaptosuccinic acid scan for at least five months after infection. Acta Paediatr 86:803-807

12. Toffolo A, Ammenti A, Montini G (2012) Long-term clinical consequences of urinary tract infections during childhood: a review. Acta Paediatr 101:1018-1031

13. Geback C, Hansson S, Martinell J, Sandberg T, Sixt R, Jodal U (2015) Renal function in adult women with urinary tract infection in childhood. Pediatr Nephrol 30:1493-1499

14. Geback C, Hansson S, Himmelmann A, Sandberg T, Sixt R, Jodal U (2014) Twenty-four-hour ambulatory blood pressure in adult women with urinary tract infection in childhood. J Hypertens 32: 1658-1664 discussion 1664

15. Piepsz A, Tamminen-Mobius T, Reiners C, Heikkila J, Kivisaari A, Nilsson NJ, Sixt R, Risdon RA, Smellie JM, Soderborg B (1998) Five-year study of medical or surgical treatment in children with severe vesico-ureteral reflux dimercaptosuccinic acid findings. International Reflux Study Group in Europe. Eur J Pediatr 157: 753-758

16. Brandstrom P, Neveus T, Sixt R, Stokland E, Jodal U, Hansson S (2010) The Swedish reflux trial in children: IV. Renal damage. J Urol 184:292-297

17. Sjostrom S, Jodal U, Sixt R, Bachelard M, Sillen U (2009) Longitudinal development of renal damage and renal function in infants with high grade vesicoureteral reflux. J Urol 181:22772283

18. Parvex P, Willi JP, Kossovsky MP, Girardin E (2008) Longitudinal analyses of renal lesions due to acute pyelonephritis in children and their impact on renal growth. J Urol 180:2602-2606 discussion 2606

19. Lebowitz RL, Olbing H, Parkkulainen KV, Smellie JM, TamminenMobius TE (1985) International system of radiographic grading of vesicoureteric reflux. International reflux study in children. Pediatr Radiol 15:105-109

20. Piepsz A, Colarinha P, Gordon I, Hahn K, Olivier P, Roca I, Sixt R, van Velzen $J$ (2001) Guidelines for ${ }^{99 \mathrm{~m}} \mathrm{Tc}$-DMSA scintigraphy in children. Eur J Nucl Med 28:BP37-BP41

21. Piepsz A, Tondeur M, Ham H (1999) Relative ${ }^{99 m}$ Tc-MAG3 renal uptake: reproducibility and accuracy. J Nucl Med 40:972-976

22. Agras K, Ortapamuk H, Naldoken S, Tuncel A, Atan A (2007) Resolution of cortical lesions on serial renal scans in children with acute pyelonephritis. Pediatr Radiol 37:153-158 